\title{
Rate dependent multicontinuum progressive failure analysis of woven fabric composite structures under dynamic impact
}

\author{
James Lua ${ }^{\mathrm{a}, *}$, Christopher T. Key ${ }^{\mathrm{a}}$, Shane C. Schumacher ${ }^{\mathrm{b}}$ and Andrew C. Hansen ${ }^{\mathrm{b}}$ \\ ${ }^{a}$ Applied Mechanics Department, System Engineering Group Anteon Corporation, Mystic, CT, USA \\ ${ }^{\mathrm{b}}$ Department of Mechanical Engineering, University of Wyoming, Laramie, Wyoming 82071, USA
}

Received 18 June 2003

Accepted 7 November 2003

\begin{abstract}
Marine composite materials typically exhibit significant rate dependent response characteristics when subjected to extreme dynamic loading conditions. In this work, a strain-rate dependent continuum damage model is incorporated with multicontinuum technology (MCT) to predict damage and failure progression for composite material structures. MCT treats the constituents of a woven fabric composite as separate but linked continua, thereby allowing a designer to extract constituent stress/strain information in a structural analysis. The MCT algorithm and material damage model are numerically implemented with the explicit finite element code LS-DYNA3D via a user-defined material model (umat). The effects of the strain-rate hardening model are demonstrated through both simple single element analyses for woven fabric composites and also structural level impact simulations of a composite panel subjected to various impact conditions. Progressive damage at the constituent level is monitored throughout the loading. The results qualitatively illustrate the value of rate dependent material models for marine composite materials under extreme dynamic loading conditions.
\end{abstract}

\section{Introduction}

The use of advanced composite materials for marine structures will not only achieve substantial space and weight savings, but will also reduce the electromagnetic signature and life cycle costs for these structures. Due to their enhanced interlaminar fracture toughness, polymer-based woven fabric composites have been used extensively in marine applications. Marine composite materials typically exhibit significant rate dependent response characteristics when subjected to extreme dynamic loading conditions $[1,10$, 12]. Damage in these composites generally initiates in the polymer matrix and significantly affects the macroscopic response long before catastrophic failure. Ma-

* Corresponding author: James Lua, 240 Oral School Road, Suite 105, Mystic, CT 06355 - 1208, USA. Tel.: +1 8605729600 X 277; Fax: +1 860572 7328; E-mail: jlua@ Anteon.com. trix damage manifests itself in the form of highly nonlinear shear behavior as well as strain rate hardening under dynamic loads. A significant concern in the application of these woven fabric composites for hull structures is how to reliably assess the nonlinear material response and damage seen in these composite hulls when subjected to extreme dynamic loads.

Currently, the lack of a reliable composite damage prediction tool forces the Navy to implement conservative designs based on expensive and time consuming test-driven certification procedures and shock qualification tests for the primary composite structural components. In the absence of structural test data, conservative design methodologies may result in substantial and unnecessary weight increases without providing a quantifiable measurement of ship structural reliability.

The optimal design of composite structures necessitates knowledge of progressive damage accumulation mechanisms occurring at the microstructural level. For 
instance, a significant damage mechanism in a weave involves matrix cracking occurring within a fiber bundle. The resulting stiffness loss from this damage accumulation can cause significant load redistribution within the material and structure. Eventually, catastrophic failure will occur due to the development of one or more areas of highly localized stress, which behave as macroscopic damage regions or cracks. The ability to accurately model the micro-damage growth, stiffness loss, load redistribution, and final rupture is essential for reliable failure prediction of woven fabric composite structures.

Primarily, two commercial codes have been used extensively by the Navy for composite ship structural analysis: ABAQUS ${ }^{1}$ and LS-DYNA. ${ }^{2}$ Macrolevel composite failure criteria such as maximum stress/strain and Tsai-Wu [13], are commonly used and supported by ABAQUS and LS-DYNA. An extensive evaluation of existing composite failure criteria and exploration of the possibilities for modification of material and failure models are given by Paris [9].

The majority of macroscopic failure criteria are empirical in nature and only determine binary type failure where the composite is either intact or failed. With extensive testing to parameterize these phenomenological models, excellent predictions of final failure may nonetheless be possible. However, from a design standpoint, this type of design tool is unappealing. Typically, significant damage at the microstructural level occurs prior to catastrophic failure. It is not uncommon to observe constituent damage at stress levels that are $25 \%$ of ultimate. In addition, the resulting test-driven failure criteria may be largely case dependent with large uncertainties associated with the material parameters.

Micromechanical modeling is differentiated from macromechanical modeling by the fact that constituent level information is retained, rather than being homogenized at the lamina level. The appeal of micromechanical modeling is that it elucidates the physics of composite material failure in that it can predict not only homogenous level failure but also constituent level failure, which is where failure often initiates in composite materials.

The advent of MCT, coupled to nonlinear finite element structural analysis codes, has opened a new window of constituent information for the composite struc-

\footnotetext{
${ }^{1}$ ABAQUS/Standard 6.1. Registered trademark of Hibbitt, Karlsson and Sorensen, Inc.

${ }^{2}$ LS-DYNA 960. Registered trademark of Livermore Software Technology Corporation.
}

tural designer. Mayes and Hansen [6-8] demonstrated MCT's high accuracy and numerical efficiency for progressive failure predictions of unidirectional composite structural laminates under static loads. Key et al. [4] extended the application of MCT to woven fabric composite materials consisting of three constituents: warp fiber bundles, fill fiber bundles, and pure matrix pockets (Fig. 1). Schumacher [11] extended the threeconstituent MCT decomposition developed by Key to access continuum stress/strain fields for the matrix material within a fiber bundle. Schumacher also implemented a strain rate hardening model with continuum damage for the matrix material within a fiber bundle. The MCT algorithm has currently been implemented in LS-DYNA using user-defined material model interfaces [5].

Applications of rate-dependent progressive failure analysis using the MCT module highlight several crucial features of the model including:

- the ability to capture the nonlinear inelastic behavior caused by matrix cracking occurring within the fiber bundles,

- qualitative prediction of the hysteresis loops associated with loading and unloading; and

- the ability to simulate strain rate hardening.

Critical features of the rate dependent MCT analysis coupled with LSDYNA3D are demonstrated via a simple one-element model of a plain weave composite. The effects of strain rate hardening are also demonstrated through the application of the model to a composite plate subjected to low and high impact velocities.

\section{Overview of conventional met}

Multicontinuum Theory (MCT) represents an attractive nonlinear modeling approach for progressive failure of composite structures. The approach is based on modeling a composite material as separate, but linked, continua comprised of the individual constituents. Retaining the constituents' identities allows one to access constituent stress and strain fields without a time penalty during the course of a routine structural finite element analysis. In a drastic departure from conventional composite material failure approaches, MCT allows the use of constituent-based failure criteria for examination of constituent level failure.

Any application of MCT requires rigorous enforcement of relations between composite properties and those of the constituents for any damage state. Mate- 


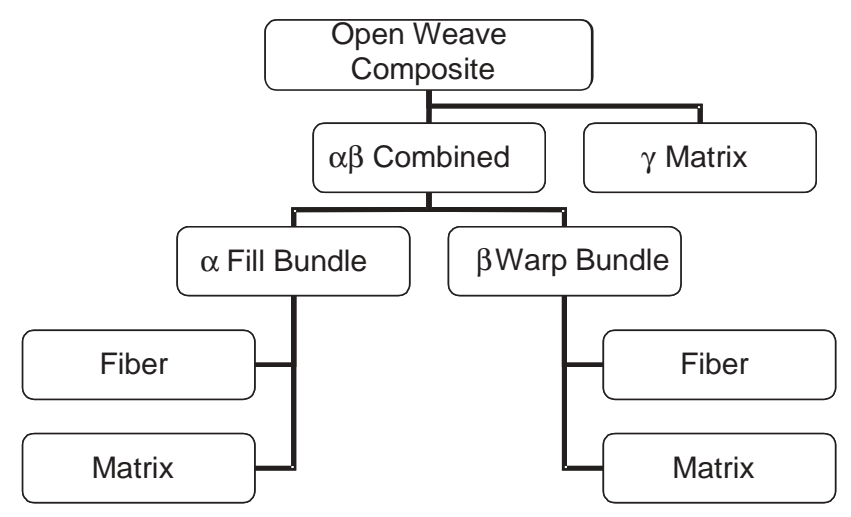

Fig. 1. Hierarchy of metrical decomposition of a plain weave, woven fabric composite.

rial properties relating the composite response to the individual constituents are accomplished using detailed finite element micromechanics. The key time saving principle to MCT is the fact that all micromechanical models are run prior to the structural analysis and are valid for any structure composed of the material of interest. For this reason, the MCT-based progressive failure analysis tool is computationally efficient for dynamic failure predictions of large scale composite ship structures.

In general, MCT failure predictions of woven fabric composites are superior to traditional continuum failure theories [14]. However, while MCT does an excellent job of predicting ultimate strengths, predicted stressstrain responses show an increased deviation from the experimental data after matrix failure begins to occur. This deviation is mainly attributed to the binary degradation scheme incorporated with the conventional MCT analysis tool. Specifically, in a conventional MCT analysis, when failure in a constituent occurs, material properties for that constituent are subsequently zeroed, rather than being degraded in a continuous manner.

\section{Overview of rate-dependent mct}

In a deviation from conventional MCT technology where only two states (failure or no failure) are considered for each constituent of the composite, the rate dependent MCT described herein uses a continuum damage mechanics approach to continuously degrade the matrix constituent properties. This MCT rate dependent material damage model for the matrix constituent utilizes a damage evolution motivated by the kinetic theory of fracture [15]. Kinetic theory is centered on bond rupture at the molecular level in a material. Bond rupture manifests itself in the form of sub-microcracks.
As loading continues, these microcracks coalesce resulting in macroscopic failure. A brief summary of the rate dependent MCT material damage model is given below. For a detailed discussion of the model the reader is referenced to Schumacher [11].

Continuum damage under uniaxial stress is modeled mathematically by introducing a crack damage state variable, $n$. A value of $n=0$ corresponds to no damage, whereas a value of $n=1$ corresponds to macroscopic failure under uniaxial stress conditions. Following Hansen and Baker-Jarvis [2], an evolution equation for the crack damage variable assumes the form

$$
\frac{d n(t)}{d t}=\left(n_{0}-n(t)\right) K_{b},
$$

where

$$
K_{b}=\frac{1}{\tau_{0}} e^{\left(\frac{-(U-\gamma \sigma)}{k T A}\right)} .
$$

In the above, $\tau_{0}$ is the period of characteristic oscillation of atoms in a solid, $k$ is Boltzmann's constant, $A$ is Avogadro's number, $T$ is the temperature, $U$ and $\gamma$ are material constants. The solution of Eq. (1) under uniaxial stress results in the well known durability equation attributed to Zhurkov [15]. Hansen and Baker-Jarvis [2] showed Eq. (1) is capable of predicting failure of PMMA (plexiglas) under creep as well as constant stress-rate conditions.

In order to characterize the damage evolution and accumulation under three-dimensional stress states, we introduce a second order continuum damage tensor, $n_{i j}$, defined by

$$
n_{i j}=\left[\begin{array}{rrr}
n_{11} & n_{12} & n_{13} \\
& n_{22} & n_{23} \\
s y m & & n_{33}
\end{array}\right] .
$$

Following the development of kinetic theory, a first order differential equation for $n_{i j}$ is postulated as 


$$
\frac{d n_{i j}(t)}{d t}=\left(n_{0}-n_{i j}(t)\right) K_{i j b}
$$

where $K_{i j b}$ is defined by

$$
K_{i k b}=\frac{1}{\tau_{0}} e^{\left(-\left(R-\beta \sigma_{i j}^{m}\right)\right)},
$$

and $R$ and $\beta$ are material constants. We allow $R$ and $\beta$ to assume different values in tension and shear, respectively.

Two points of interest are noted here. First, experimental observation of woven fabric composites indicates damage due to matrix cracking occurs in the matrix material within fiber bundles. In contrast, no visual damage is observed in the large matrix pockets occurring within the weave. The experimental observations noted here have been confirmed by finite element micromechanics of woven fabrics. That is, matrix stress levels within a fiber bundle are much higher than those associated with pure matrix pockets. Therefore, the damage model proposed in Eq. (4) applies to the matrix material within a fiber bundle. As such, the stress tensor $\sigma_{i j}^{m}$ represents the matrix stress within a fiber bundle.

A second aspect of the failure analysis is that one must distinguish between damage as modeled by the damage tensor and complete failure of the matrix. As damage accumulates, a critical level of damage facilitates catastrophic failure of the matrix material. With the introduction of a second order continuum damage tensor, one must develop an interactive damage failure criterion where all components of damage contribute to the overall failure. The damage failure criterion is addressed later in the paper.

\subsection{Damage based material property degradation for unidirectional composites}

A central assumption in the proposed damage analysis is that the fiber bundles remain transversely isotropic as damage accumulates. To retain transverse isotropy, both the matrix material degradation and failure criteria are formulated based on the transversely isotropic damage invariants, which are the quadratic functions of the damage tensor $\left(n_{i j}\right)$. For this work it was assumed that the damage in the direction of the fibers has minimal effect on the stiffness of the composite in this direction. Hence, the damage variable $n_{11}$ is neglected. Therefore, the quadratic transverse isotropic damage invariants that contribute to the material degradation are given by

$$
I_{2}^{m}=n_{22}^{m}+n_{33}^{m}
$$

$$
\begin{aligned}
& I_{3}^{m}=\left(n_{22}^{m}\right)^{2}+\left(n_{33}^{m}\right)^{2}+2\left(n_{23}^{m}\right)^{2} \\
& I_{4}=\left(n_{12}^{m}\right)^{2}+\left(n_{13}^{m}\right)^{2} .
\end{aligned}
$$

As damage in the matrix material accumulates, the matrix stiffness properties must be degraded to reflect reduced stiffness. The degradation scheme relies on degrading the matrix properties within a fiber bundle. This degradation in turn affects the unidirectional properties of the fiber bundle. This link is established through micromechanics of a unidirectional continuous fiber composite. The degraded bundle properties in turn affect the overall composite properties. The degradation scheme is complex and the details behind the entire process are outlined in Schumacher [11].

\subsection{Failure criteria for the fiber and matrix constituent in a woven fabric composite}

For the case of fiber failure, a binary convention (failure or no failure) is used. The failure criterion is formulated based on the transversely isotropic stress invariants for the fiber stress field.

Assuming the fibers in the local material coordinate system are along the $\mathrm{x} 1$-direction, the fiber failure criterion used for the woven fabric composite is given by [3]

$$
{ }^{ \pm} A_{1}^{f}\left(I_{1}^{f}\right)^{2}+A_{4}^{f} I_{4}^{f}=1,
$$

where $I_{1}^{f}$ and $I_{4}^{f}$ are computed from the fiber state of stress $\left(\sigma_{i j}^{f}\right)$, and are defined by

$$
\begin{aligned}
& I_{1}^{f}=\sigma_{11}^{f}, \\
& I_{4}^{f}=\left(\sigma_{12}^{f}\right)^{2}+\left(\sigma_{13}^{f}\right)^{2} .
\end{aligned}
$$

The coefficients $\pm A_{1}^{f}$ and $A_{4}^{f}$ given in Eq. (9) are functions of the fiber ultimate strengths $\left(S_{i j}^{f}\right)$ and are given by

$$
\begin{aligned}
& { }^{ \pm} A_{1}^{f}=\frac{1}{\left( \pm S_{11}^{f}\right)^{2}} \\
& A_{4}^{f}=\frac{1}{\left(S_{12}^{f}\right)^{2}} .
\end{aligned}
$$

In the above, the \pm symbol indicates either a tensile or compressive loading situation.

For the situation of matrix failure, the unidirectional failure criteria developed by Mayes and Hansen [6] in stress space is modified by replacing the matrix stress tensor $\left(\sigma_{i j}^{m}\right)$ with the matrix damage tensor $\left(n_{i j}^{m}\right)$ and applying this at the bundle level. For the matrix in each 


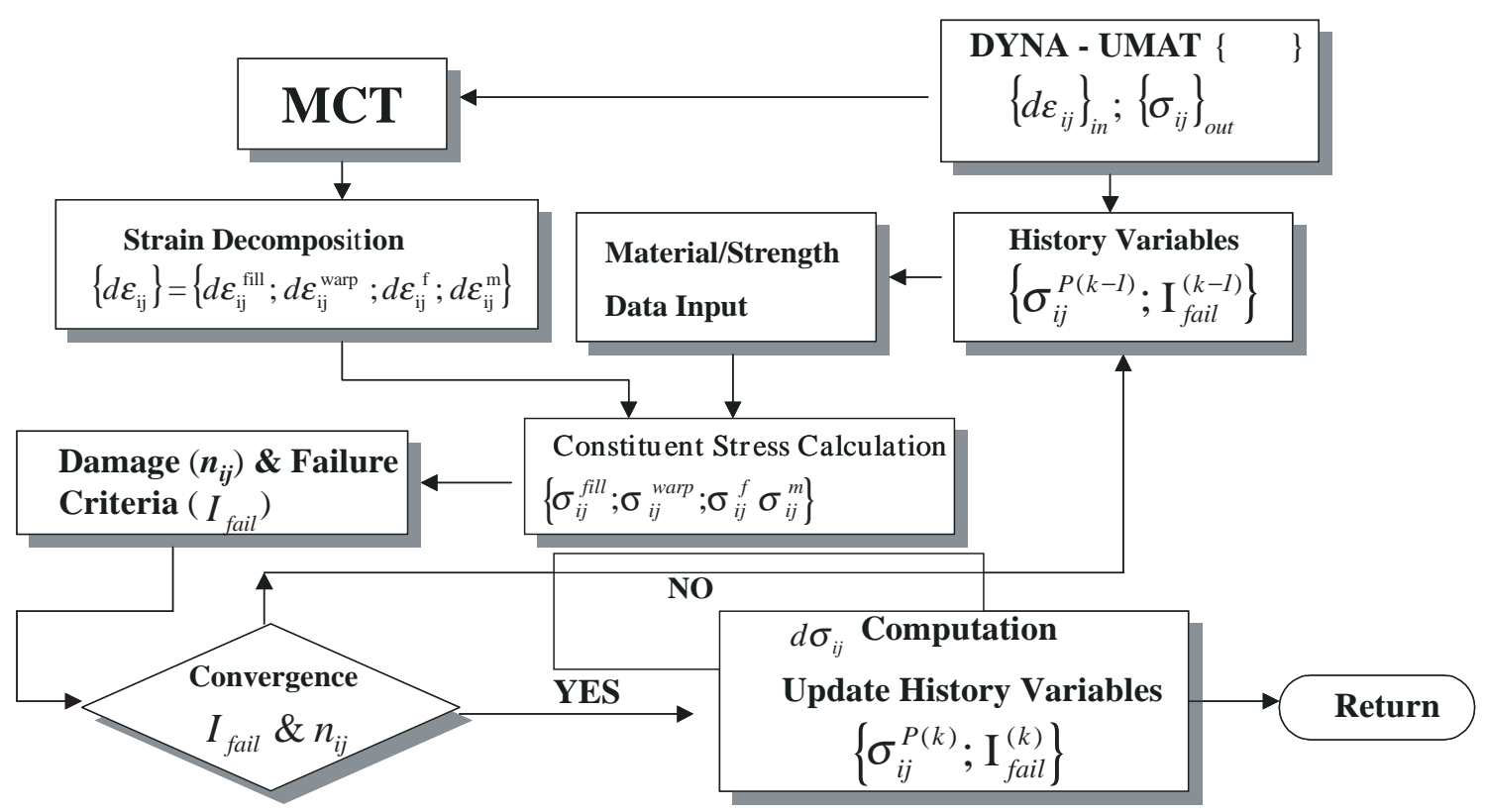

Fig. 2. A Logic Diagram for umat41 Routine in LSDYNA-MCT.

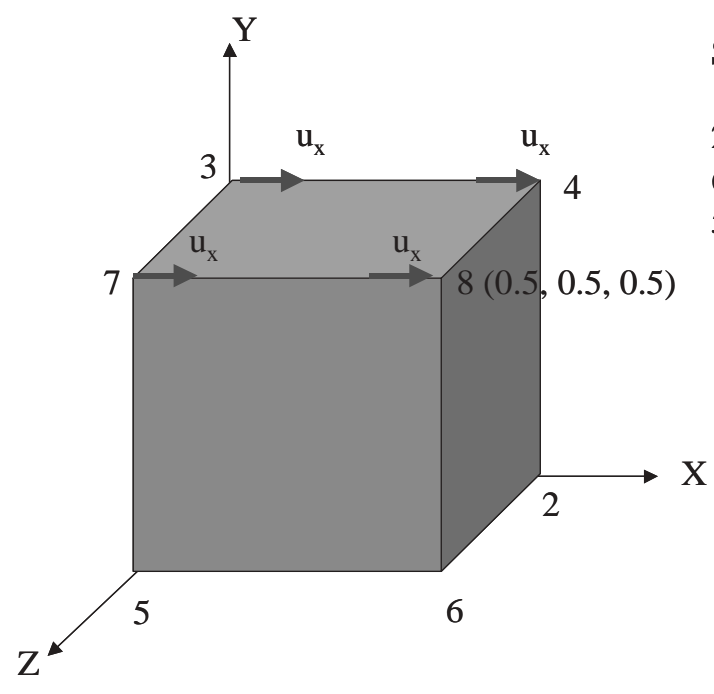

SPCs at Bottom Nodes

$1\left(\begin{array}{lll}1 & 1 & 1\end{array}\right)$

2 (1 110$)$

6 ( $\left.\begin{array}{lll}1 & 1 & 0\end{array}\right)$

5 (1 110$)$

Deformation Function

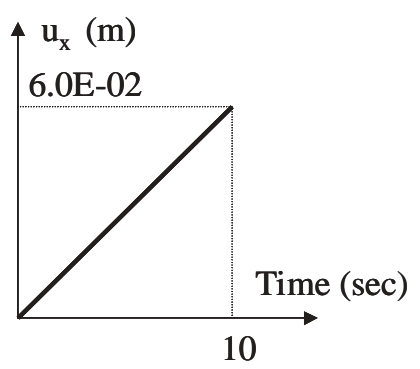

Fig. 3. Display of a one-element model for in-plane shear in xy-plane.

bundle, failure is assumed to occur when the accumulated damage in the matrix phase achieves some critical values. In direct correlation with Mayes, the matrix failure criterion based on damage can be expressed by

$$
{ }^{ \pm} A_{2}^{m}\left(I_{2}^{m}\right)^{2}+A_{3}^{m} I_{3}^{m}+A_{4}^{m} I_{4}^{m}=1,
$$

where $I_{2}^{m}, I_{3}^{m}$, and $I_{4}^{m}$ are the transversely isotropic damage invariants defined by Eqs (6-8).

Again, in accordance with the work of Mayes, the coefficients $A_{i}^{m}$ are determined from unidirectional com- posite experimental stress-strain behavior. For example, a transverse tensile loading case is used to determine the coefficient $A_{2}^{m}$, as

$$
\begin{aligned}
{ }^{ \pm} A_{2}^{m}= & \frac{1}{\left({ }^{ \pm} F_{22}^{22 m}+{ }^{ \pm} F_{33}^{22 m}\right)^{2}} \\
& \left(1-\frac{\left({ }^{ \pm} F_{22}^{22 m}\right)^{2}+\left({ }^{ \pm} F_{33}^{2 m}\right)^{2}}{2\left(F_{23}^{m}\right)^{2}}\right) .
\end{aligned}
$$

The coefficients $F_{j j}^{i i m}$ represent the critical values 
of damage as determined from stress-strain experimental data. The double subscript notation is necessary to identify the damage term and the loading direction. In particular, $F_{33}^{22 m}$ represents damage in the 33 direction as the result of a stress in the 22 direction. Such notation is necessary because the stress state in the matrix material is fully three-dimensional under uniaxial bundle stress.

For the case of out-of-plane shear (transverse shear), the critical coefficient $A_{3}^{m}$ is given by

$$
A_{3}^{m}=\frac{1}{2\left(F_{23}^{m}\right)^{2}} \text {. }
$$

In the case of in-plane shear (longitudinal shear), the calculation of the critical coefficient, $A_{4}^{m}$ is given by

$$
A_{4}^{m}=\frac{1}{\left(F_{12}^{m}\right)^{2}} \text {. }
$$

In summary, both the fiber and matrix failure criteria are formulated based on the transversely isotropic stress and damage invariants at the corresponding constituent level. The use of a damage based criteria for the matrix constituent is the main departure from conventional MCT where all failure criteria are formulated in terms of stress invariants.

\subsection{Summary of numerical procedures associated with the rate-dependent MCT material damage model}

The key numerical steps in implementing the ratedependent MCT material damage model for failure predictions of woven fabric composites at a given stress level are summarized below.

- Given the composite level stress, compute the stress in the warp $(x)$ and fill $(y)$ tows (bundles) and in the pure matrix phase.

- Given the tow stress, compute the stress in the tow-fiber and the tow-matrix

- Based on the calculated matrix stress within a tow, compute the damage tensor along with its invariants using the damage evolution law.

- Determine the degraded matrix material properties based on the current damage level.

- Determine the failure state using the constituentbased failure criteria from the constituent stress/ damage and constituent strengths.

- According to the failure state, compute the damaged composite material properties based on the pre-defined parameters.

- Compute the composite strain response based on the determined composite material properties and the given composite level stress.

\section{Implementation of rate-dependent mct with Isdyna3d}

The rate-dependent MCT material damage module outlined above is embedded as a user-defined material model within the commercial explicit finite element code LSDYNA3D. The implementation of the rate dependent MCT module with LSDYNA is achieved through the user-defined material models available in material types 41 to 50 in LSDYNA. For this integration, the umat 41 user-defined subroutine was developed for implementing the rate-dependent MCT module in LSDYNA3D.

Within the umat41 material subroutine the ratedependent MCT algorithm consists of the following key solution modules:

- Data Input Module - Used to input composite and constituent material properties at various pre-defined failure states, strength parameters of each constituent, parameters for computing degraded composite properties, and damage parameters used in the matrix damage evolution law;

- Matrix Computation Module - Used to calculate the composite stiffness matrices and strain decomposition matrices at various failure states;

- Strain Decomposition Module - Used to compute the constituent stress and strain increments for a given composite strain increment and damage/failure state;

- Damage Computation Module - Used to calculate the damage tensor $\left(n_{i j}\right)$ along with its invariants in the matrix phase of the bundle;

- Failure Prediction Module - Used to predict the failure state in the matrix and fiber constituents;

- Material Degradation Module - Used to computed the degraded composite material properties based on the damage/failure in the matrix and fiber constituents; and

- Iterative Solution Module - Used to perform an iterative solution process to ensure a convergent solution in the predicted failure state and damage variables at the current time step.

Using these solution modules as basic building blocks, the structure of umat41 is shown in Fig. 2.

In the material subroutine, umat41, a set of history variables (HISV) is used to store the total constituent stresses and failure states for each Gauss point at each time increment of the analysis. Given these history variables, the numerical procedure for computing the total composite stress for a given composite strain increment within the umat41 subroutine is summarized below: 


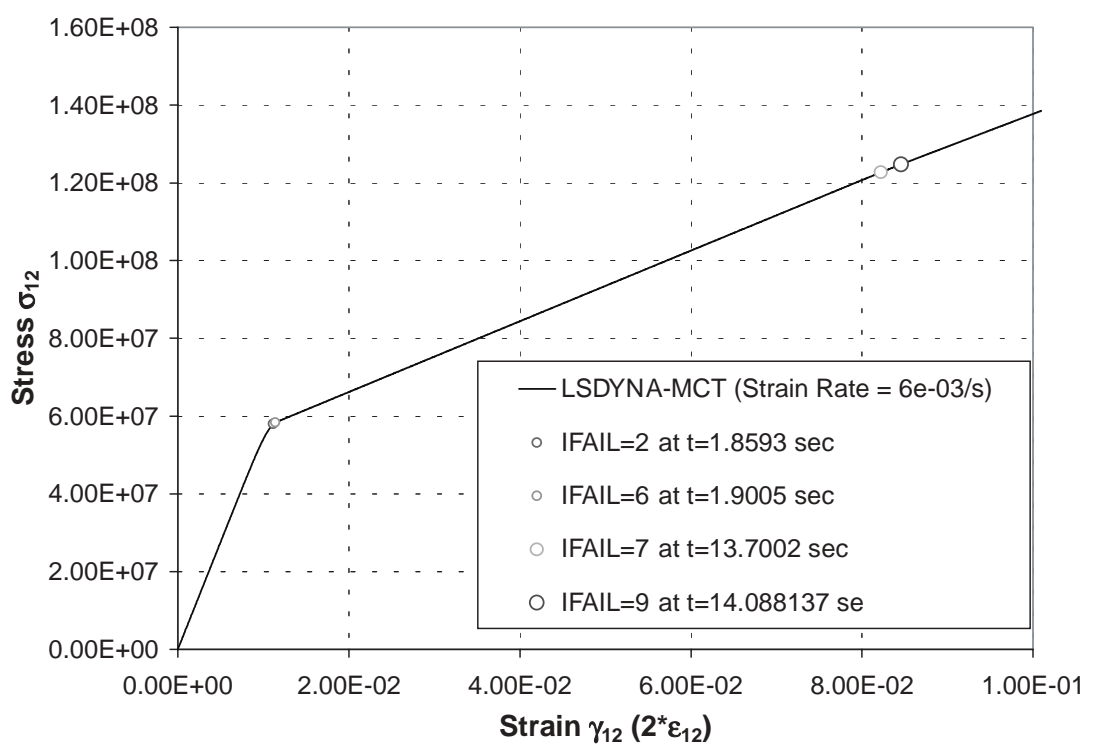

Fig. 4. $\sigma_{12}-\gamma_{12}$ response prediction of a plain weave woven fabric composite subjected to in-plane shear with the strain rate of $6 \mathrm{e}-03 / \mathrm{s}$.

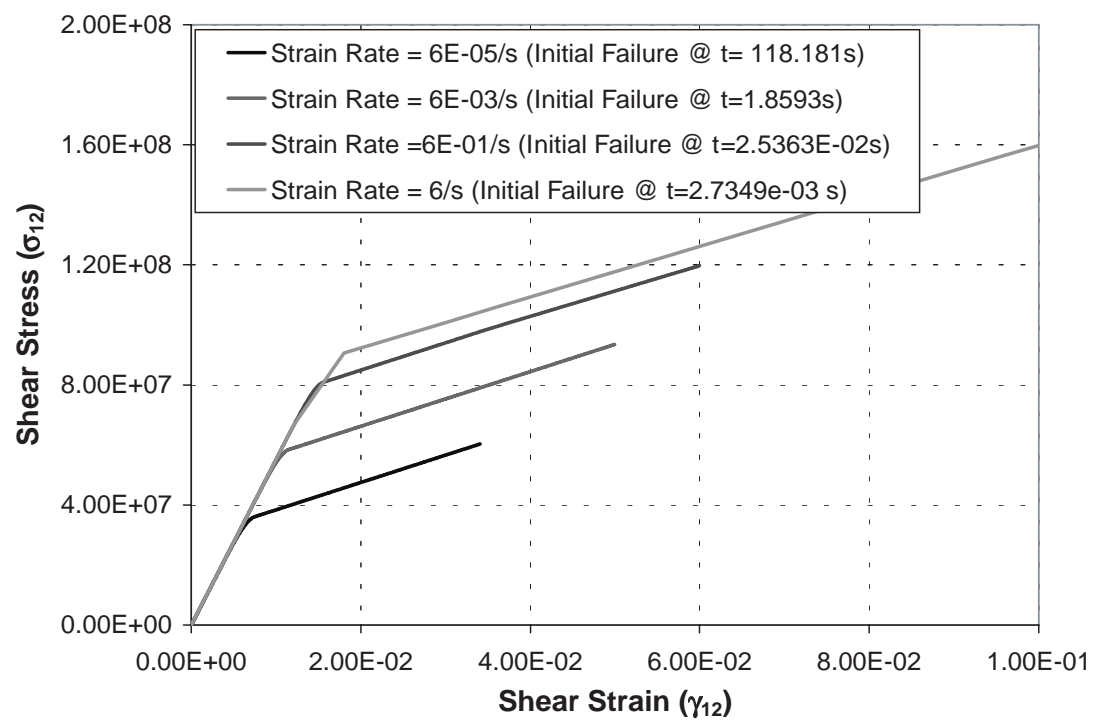

Fig. 5. Comparison of shear stress-strain response at various strain rates.

- Given the composite strain increment and the history variables from the $(\mathrm{k}-1)$ th iteration, compute the stress and strain increments in each constituent using the constituent material properties associated with the (k-1)th failure and damage states;

- Compute the total constituent stress by adding the stress increment to the corresponding total stress at the previous time step;

- Compute the damage tensor and check the matrix/fiber failure state for the present kth iteration;
- Update the constituent and composite stiffness matrices based on the newly determined damage/failure states of each constituent;

- Check the convergence by comparing the failure state and damage tensor from the kth iteration with the corresponding results at the (k-1)th iteration;

- If convergence has been achieved, save the failure state and constituent stress in the HISV array. Otherwise a new iteration will be started using the newly determined failure state and degraded constituent stiffness matrices. 
Table 1

Material properties of composite and its constituents at its virgin state

\begin{tabular}{cccc}
\hline Material properties & Composite & Fiber & Matrix \\
\hline $\mathrm{E}_{11}(\mathrm{GPa})$ & 26.5 & 71.0 & 4.66 \\
$\mathrm{E}_{22}(\mathrm{GPa})$ & 25.5 & 71.0 & 4.66 \\
$\mathrm{E}_{33}(\mathrm{GPa})$ & 15.3 & 71.0 & 4.66 \\
$v_{12}$ & 0.154 & 0.26 & 0.292 \\
$v_{13}$ & 0.292 & 0.26 & 0.292 \\
$v_{23}$ & 0.292 & 0.26 & 0.292 \\
$\mathrm{G}_{12}(\mathrm{GPa})$ & 5.52 & 28.2 & 1.80 \\
$\mathrm{G}_{13}(\mathrm{GPa})$ & 7.74 & 28.2 & 1.80 \\
$\mathrm{G}_{23}(\mathrm{GPa})$ & 7.74 & 28.2 & 1.80 \\
\hline
\end{tabular}

\section{One-element model validation of the rate dependent mct damage model}

In order to demonstrate the applicability of the LSDYNA-MCT progressive failure module and explore the impact of strain rate on composite failure predictions, a simple one-element model for the plain weave composite is used. Initially, we consider a pure in-plane shear loading condition as shown in Fig. 3, where we see the element geometry, boundary conditions, prescribed nodal displacements and their corresponding deformation function. The material system of interest for the model is an E-glass/8084 plain weave composite material with an overall fiber volume fraction of $50 \%$ and a bundle fiber volume fraction of $75 \%$ with a density of $1,811 \mathrm{~kg} / \mathrm{m}^{3}$. The material properties of the composite system and its constituents are listed in Table 1.

The tensile and compressive axial strengths of the Eglass fibers are $1.507 \mathrm{GPa}$ and $1.399 \mathrm{GPa}$, respectively, while the in-plane shear strength is $120.0 \mathrm{MPa}$. For the current qualitative study, the damage parameters of the matrix material obtained from experimental testing and best estimations are listed in Table 2 .

Under the prescribed displacement boundary condition shown in Fig. 3, the resulting rate of engineering shear strain $\left(\gamma_{12}=2 * \varepsilon_{12}\right)$ is $6 \mathrm{e}-03 / \mathrm{sec}$. For this analysis, initial failure occurs at $t=1.859 \mathrm{sec}$ as matrix failure in the $\mathrm{x}$-tow. Subsequent failures include matrix failure in both the $\mathrm{x}$ - and $\mathrm{y}$ - tows at $t=1.901 \mathrm{sec}$, fiber breakage in the y-tow at $t=13.70 \mathrm{sec}$, and final catastrophic failure at $t=14.09 \mathrm{sec}$. The shear stressstrain prediction using LSDYNA-MCT along with the associated failure events are shown in Fig. 4.

In order to demonstrate the capability of the ratedependent MCT material damage model to capture the strain rate hardening effect, the one-element model shown in Fig. 3 is modeled again with in-plane shear strain rates $\left(\dot{\gamma}_{12}\right)$ of $6 \mathrm{e}-05 / \mathrm{s}, 6 \mathrm{e}-03 / \mathrm{s}, 6 \mathrm{e}-01 / \mathrm{s}$, and $6.0 / \mathrm{s}$. A summary of the failure sequence at these four strain rates is given in Table 3. For all strain rates less than $6.0 / \mathrm{s}$, failure in the model initiates as matrix failure in the $\mathrm{x}$-tow followed by matrix failure in the $\mathrm{y}$-tow. However, at the highest strain rate of $6.0 / \mathrm{s}$, both matrix failure and fiber breakage occur simultaneously in the y-tow. In addition, there is almost no time difference between the initial failure and the final rupture, which indicates the enhanced brittle failure mechanism.

Figure 5 illustrates the capability of the rate dependent MCT material damage model to predict failure under various loading conditions where strain rate hardening may exist. In Fig. 5, both the initial failure stress and the ultimate strength increase with the increase of the applied strain rate. Therefore, the use of quasistatic constitutive behavior to predict the response of a composite structure subjected to extreme dynamic loading will generally result in a conservative prediction. Based on these findings, the rate dependent MCT material damage module described in the article could be a valuable tool for the progressive failure prediction of marine composite structures under these types of loading conditions.

\section{Response and failure prediction of a composite panel subjected to high and low projectile impact velocities}

To validate the rate dependent MCT material damage model at a structural level we next considered the situation of both high and low velocity impact of a composite panel. The same material system used for the one element demonstration was used again for this structural investigation. In this analysis, a square panel with a length of $0.305 \mathrm{~m}$ and a thickness of $17.78 \mathrm{~mm}$ was studied. The square panel was simply supported on top of a rigid ring with a diameter of $0.305 \mathrm{~m}$. There were 12 plies for the composite plate with a lamination sequence of $6[0 / 90]$. Each ply was discretized into 2 elements through the thickness direction.

The impactor for this study was a projectile with a radius of $6.3 \mathrm{~mm}$ and height of $12.75 \mathrm{~mm}$. A simple contact boundary condition was modeled between the flat nose of the projectile and the outer surface of the panel. The elastic modulus, Poisson's ratio, yield strength, and the density of the projectile were $207 \mathrm{GPa}$, $0.33,1.03 \mathrm{GPa}$ and $7877 \mathrm{~kg} / \mathrm{m}^{3}$, respectively. To start the contact and impact analysis, the initial velocity of the projectile was prescribed. Two impact scenarios were used to explore the composite plate response when subjected to both low and high strain rates. Both the 
Table 2

List of Parameters Used in Damage Characterization of Matrix

\begin{tabular}{lcc}
\hline Damage Parameters of Matrix & $\begin{array}{c}\text { Normal Mode } \\
\left(\sigma_{11}, \sigma_{22}, \text { or } \sigma_{33}\right)\end{array}$ & $\begin{array}{c}\text { Shear Mode } \\
\left(\tau_{12}, \tau_{13}, \text { or } \tau_{23}\right)\end{array}$ \\
\hline Initial damage $\left(n_{0}\right)$ & 1.58 & 1.58 \\
Material constant $\mathrm{R}$ & 46.93 & 40.43 \\
Material constant $\beta(1 / \mathrm{MPa})$ & $4.01 \mathrm{E}-07$ & $3.01 \mathrm{E}-07$ \\
Period of characteristic oscillation of atoms & $1.0 \mathrm{E}-13$ & $1.0 \mathrm{E}-13$ \\
in solid $\tau_{0}(\mathrm{sec})$ & 0.216 & 0.86 \\
Ultimate damage $\mathrm{n}^{*}$ & 0. \\
\hline
\end{tabular}

Table 3

Summary of failure sequence at various strain rates

\begin{tabular}{ccccc}
\hline Strain Rate $\left(\mathrm{sec}^{-1}\right)$ & $\begin{array}{c}\text { Failure Time for matrix } \\
\text { failure in x-tow }(\mathrm{sec})\end{array}$ & $\begin{array}{c}\text { Failure Time for matrix } \\
\text { failure in y-tow }(\mathrm{sec})\end{array}$ & $\begin{array}{c}\text { Failure Time for fiber } \\
\text { breakage in the y-tow }(\mathrm{sec})\end{array}$ & $\begin{array}{c}\text { Failure Time for } \\
\text { catastrophic failure }(\mathrm{sec})\end{array}$ \\
\hline $6.0 \mathrm{E}-05$ & 118.2 & 122.3 & - & - \\
$6.0 \mathrm{E}-03$ & 1.859 & 1.901 & 13.70 & 14.09 \\
$6.0 \mathrm{E}-01$ & $2.536 \mathrm{e}-02$ & $2.578 \mathrm{e}-02$ & $5.753 \mathrm{e}-02$ & $6.141 \mathrm{e}-02$ \\
6.0 & \multicolumn{2}{c}{$t=2.735 \mathrm{e}-03 \mathrm{sec}$} & \multicolumn{2}{c}{$t=2.776 \mathrm{e}-03 \mathrm{sec}$} \\
\hline
\end{tabular}

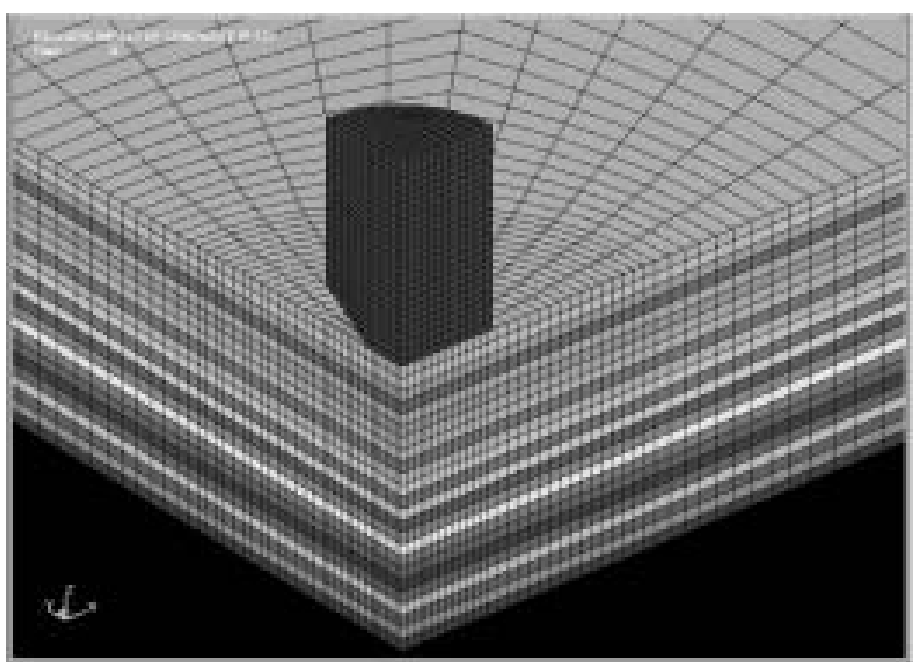

(a)

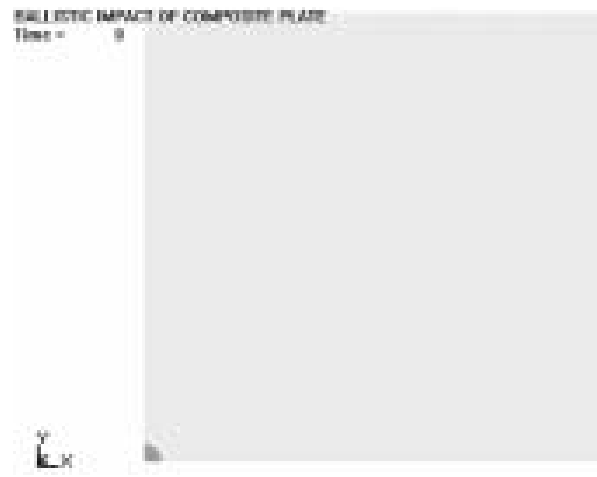

(b)

Fig. 6. LSDYNA-model for a quarter scale plate/projectile system: (a) Close-up view of contact zone; and (b) top view.

initial impact velocity and the density of the projectile were determined in such a way that the resulting total kinetic energy of the projectile before the impact was identical. The initial velocity $\left(V_{0}\right)$ and the associated density $(\rho)$ of the projectiles are given by

$$
\left\{V_{0}, \rho\right\}_{1}=\left\{50.80 \mathrm{~m} / \mathrm{s} ; 7.877 E+05 \mathrm{~kg} / \mathrm{m}^{3}\right\}
$$

for the low velocity situation, and by

$$
\left\{V_{0}, \rho\right\}_{2}=\left\{508 \mathrm{~m} / \mathrm{s} ; 7.877 E+03 \mathrm{~kg} / \mathrm{m}^{3}\right\}
$$

for the high velocity situation. As can be seen from Eqs (18) and (19), the initial projectile velocity for the second impact scenario is 10 times higher than the first, while the corresponding density is $1 / 100$ th of the first.

In order to simulate the true failure mechanism in the panel, an elastoplastic material model with kinematic hardening was used for the projectile. The associated plastic tangent hardening modulus and the hardening parameter are $34.48 \mathrm{GPa}$ and 1.0 , respectively. An eroding contact algorithm provided within LSDYNA is used in conjunction with the rate-dependent MCT progressive failure module to characterize penetration rupture of the composite near the contact/impact zone. The symmetry of the problem, allowed a quarter scale 


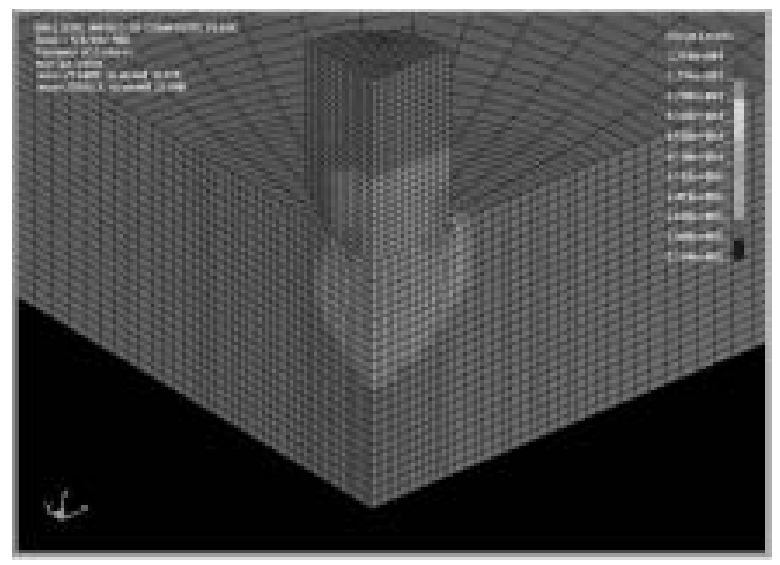

(a) $t=9.9703 \mathrm{E}-06 \mathrm{sec}$

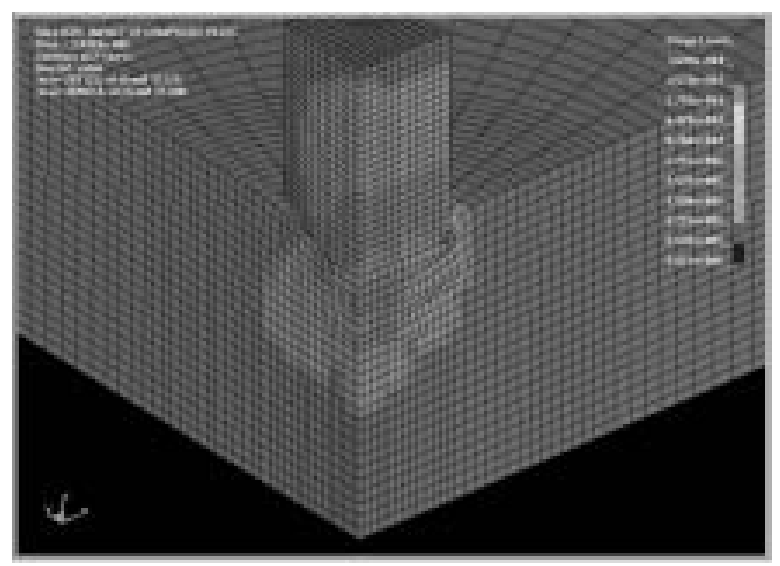

(c) $t=3.9969 \mathrm{E}-05 \mathrm{sec}$

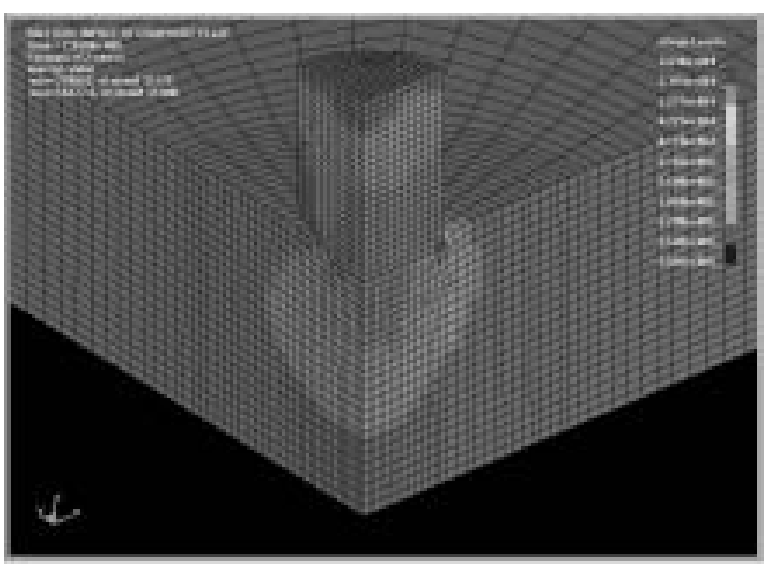

(b) $t=2.9999 \mathrm{E}-05 \mathrm{sec}$

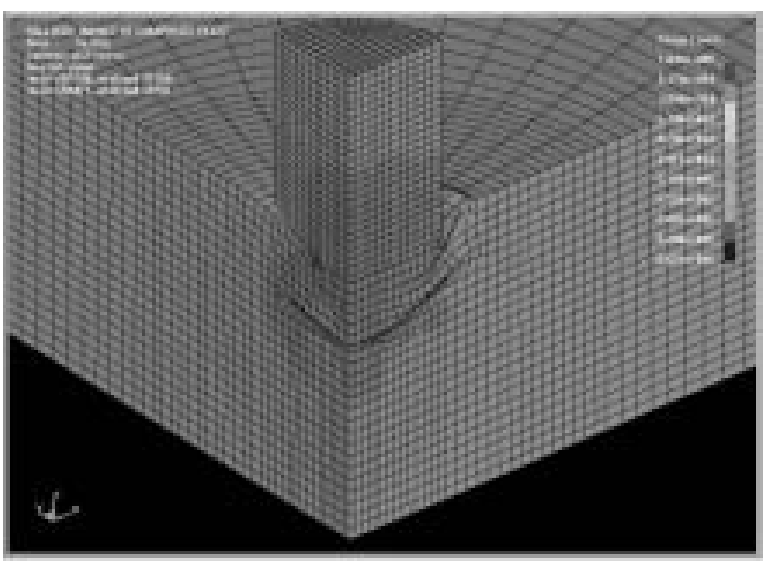

(d) $t=5.0 E-05 \mathrm{sec}$

Fig. 7. Deformed shapes and $\sigma_{z z}$ distribution at $t=9.970 \mathrm{e}-06 \mathrm{sec}, 2.999 \mathrm{e}-05 \mathrm{sec}, 3.997 \mathrm{e}-05 \mathrm{sec}$, and $5.0 \mathrm{e}-05 \mathrm{sec}$.

FEM model of the impact system to be used, as shown in Fig. 6. In addition to the 24 elements used through the thickness direction, a refined mesh is introduced near the contact/impact zone.

The deformed shape at four increasing time steps along with the distribution of the through-the-thickness stress component $\left(\sigma_{z z}\right)$ for this analysis is shown in Fig. 7. As seen in Fig. 7, the higher compressive stress zone evolves during the penetration process. In addition, due to the severe shear deformation near the edge of the contact zone, higher localized stress concentration can be observed in Fig. 7. To further illustrate the stress concentration near the edge of the contact zone, the distributions of $\sigma_{y y}$ and $\sigma_{y z}$ stress on the top layer of elements of the first ply directly underneath the projectile are shown at $t=3 \mathrm{e}-05 \mathrm{sec}$ in Fig. 8. Again, localized higher stress zones can be observed near the edge of the contact zone.

The time histories of normal strains $\left(\varepsilon_{x x}, \varepsilon_{y y}, \varepsilon_{z z}\right)$ and the shear strains $\left(\varepsilon_{x y}, \varepsilon_{y z}, \varepsilon_{z x}\right)$ of element 2184 shown in Fig. 8 are depicted in Fig. 9. As shown in Fig. 9, the dominant axial and shear strains at element 2184 are $\varepsilon_{z z}$ and $\varepsilon_{y z}$, respectively. A small jump in the strain response at $t=3.5 \mathrm{e}-05 \mathrm{sec}$ indicates a partial failure while a significant jump near $t=5.0 \mathrm{e}-05 \mathrm{sec}$ reflects complete failure of the element. Also shown in Fig. 9, the strain rates of $\varepsilon_{z z}$ and $\varepsilon_{y z}$ under the $50.8 \mathrm{~m} / \mathrm{s}$ impact velocity are about $8065 / \mathrm{s}$ and $6723 / \mathrm{s}$, respectively.

In order to explore the rate-dependent material response, the impact model shown in Fig. 6 was reanalyzed using the second impact condition given by Eq. (19). For this loading condition the deformed shape 

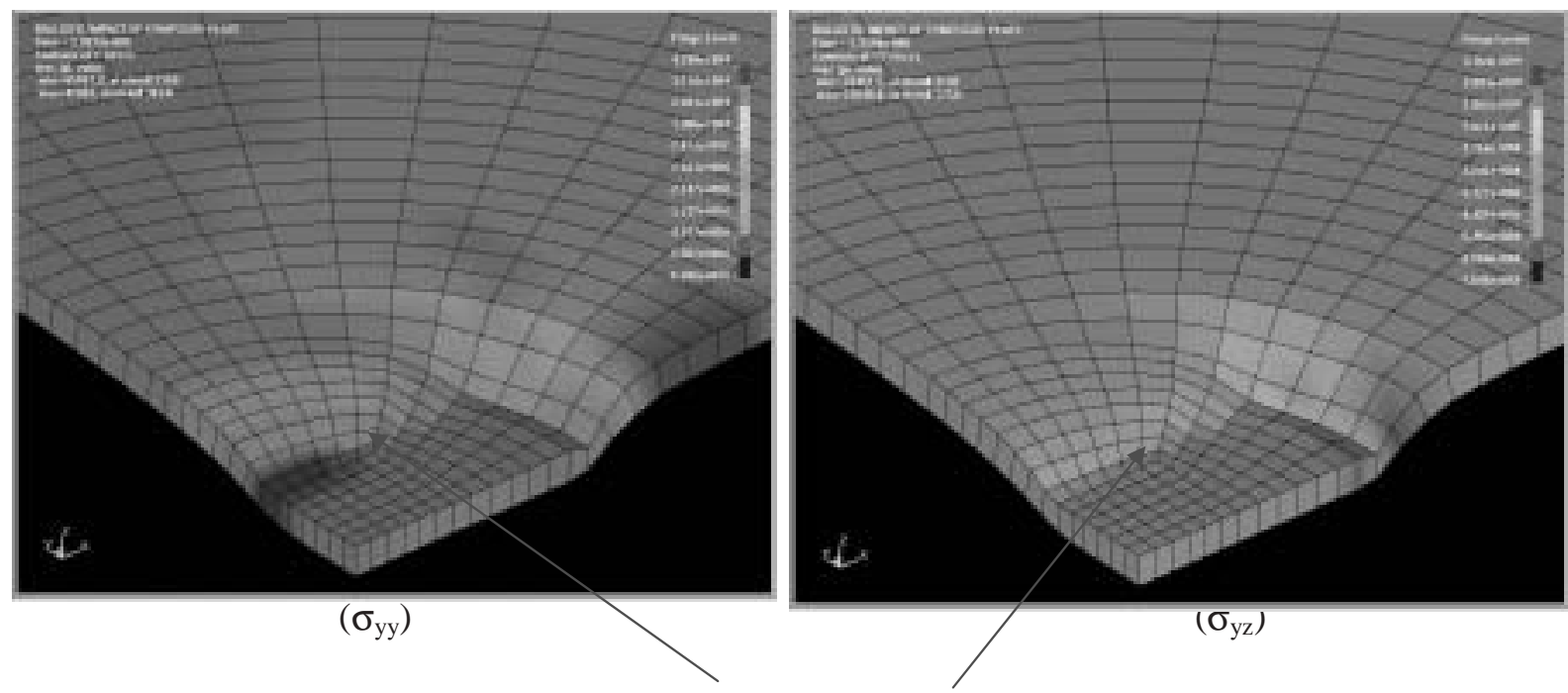

Element 2184

Fig. 8. $\sigma_{y y}$ and $\sigma_{y z}$ stress distributions on the top layer of the 1 st ply at $t=3.0 \mathrm{e}-05 \mathrm{~s}$.

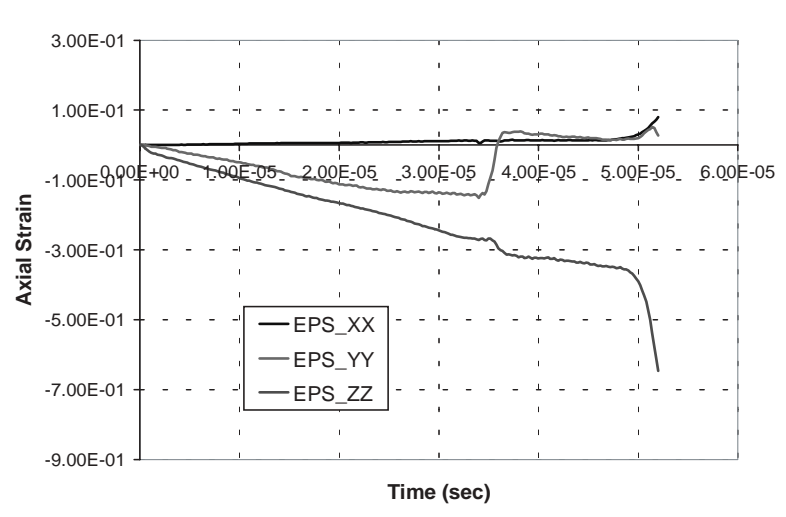

(a) Axial Strains

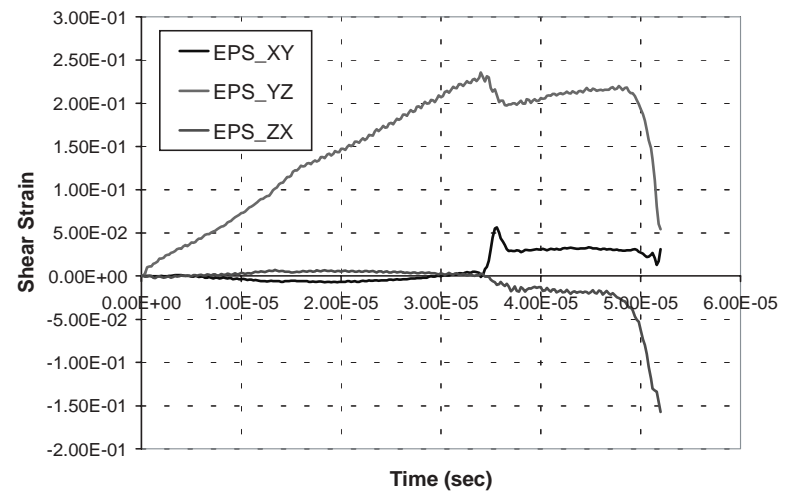

(b) Shear Strains

Fig. 9. Time histories of strain components in element 2184: (a) axial strains; and (b) shear strains.

and the distribution of dominant stress components at $t=1.0 \mathrm{e}-05 \mathrm{sec}$ are shown in Fig. 10. To demonstrate the rate dependent material response, a time history comparison of the shear strain $\left(\varepsilon_{y z}\right)$ at element 2184 for the two different impact velocities is shown in Fig. 11. Despite both projectiles having the same initial kinetic energy, the shear strain rate $\left(\dot{\varepsilon}_{y z}\right)$ resulting from the higher impact velocity is about 18 times higher then the corresponding shear strain rate under the lower impact velocity. A comparison of the shear strain/stress response resulting from these two initial impact velocities is shown in Fig. 12. As seen in Fig. 12, the yield point in the shear stress-strain curve rises from approximately $0.55 \mathrm{GPa}$ to approximately $0.69 \mathrm{GPa}$ when the initial impact velocity $\left(V_{0}\right)$ changes from $50.8 \mathrm{~m} / \mathrm{s}$ to $508 \mathrm{~m} / \mathrm{s}$. Thus, we can conclude that the MCT-rate dependent progressive failure module is capturing the strain hardening effect.

The rate dependent material response should also have a large impact on the contact force between the projectile and the composite plate. A comparison of the time history of the z-component of the total contact force $\left(F_{z}\right)$ shown in Fig. 13 confirms this result. Unlike the case of the low velocity impact where the contact force, $F_{z}$, gradually increases with the time, the rapid change in the time history of $F_{z}$ for the high velocity case is mainly attributed to the counteracting effects from the material damage in the vicinity of the 


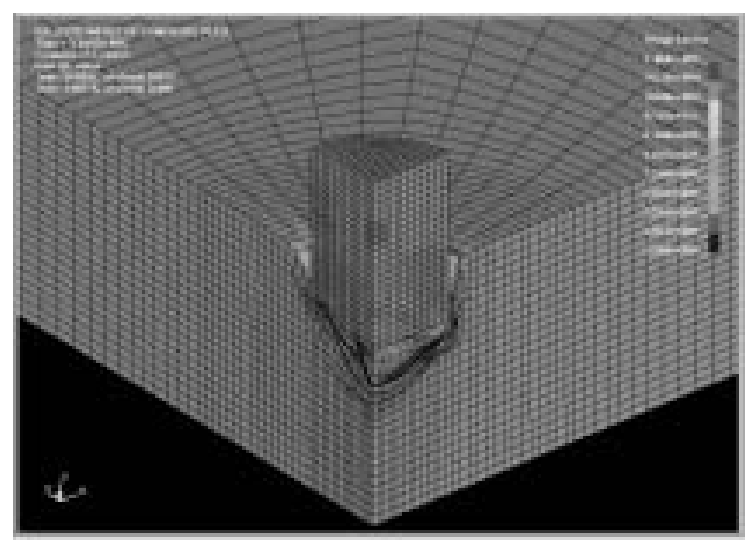

$\left(\sigma_{\mathrm{zz}}\right)$

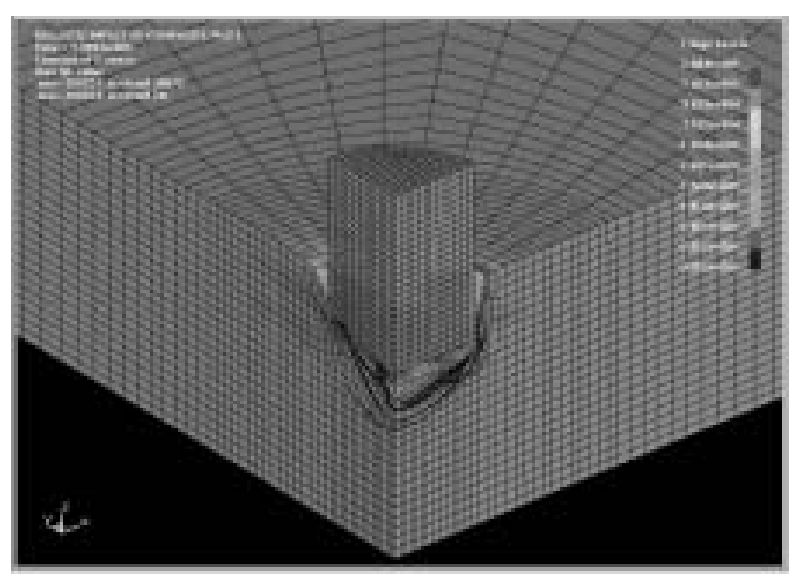

$\left(\sigma_{\mathrm{yy}}\right)$

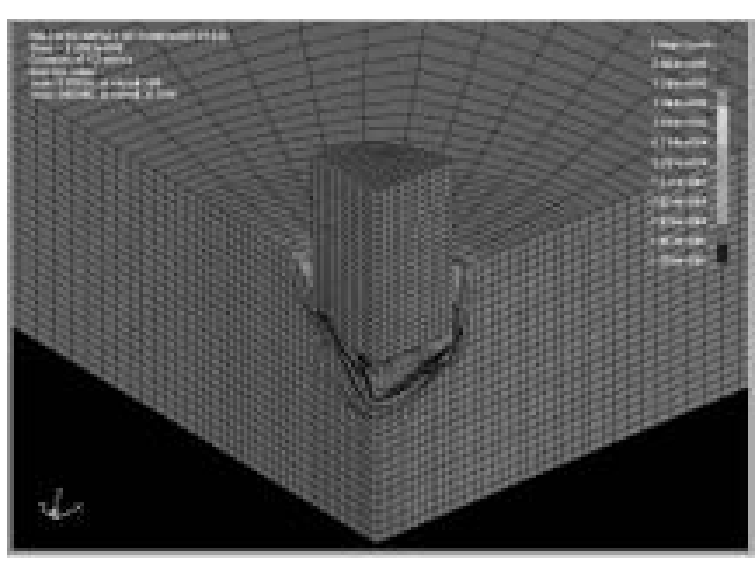

$\left(\sigma_{\mathrm{yz}}\right)$

Fig. 10. Deformed shape and stress distribution at $t=1.0 E-05 \mathrm{sec}$ under initial impact velocity $V_{0}=508 \mathrm{~m} / \mathrm{s}$.

contact zone and the strain rate hardening. Except near $t=1.28 \mathrm{e}-05 \mathrm{sec}$, the magnitude of $F_{z}$ is generally much higher for the higher velocity impact. This larger impact force indicates a higher resistance to the in-coming projectile. A comparison of the time history of the z-component of the projectile velocity $\left(V_{z}\right)$ is given in Fig. 14. As can be seen from Fig. 14, $V_{z}$ of the projectile under the lower impact velocity remains approximately the same as the initial impact velocity within the first 20 nanoseconds. However, under the higher impact velocity, $V_{z}$ of the projectile gradually decreases with $V_{z}=381.67 \mathrm{~m} / \mathrm{s}$ at $t=18.4$ nanoseconds. The $25 \%$ drop in $V_{z}$ of the projectile within the first 20 nanoseconds is mainly attributed to the effect of the strain rate hardening at the higher impact velocity.

Due to the effect of the strain rate hardening within the composite panel, the energy of the projectiles is stored in different ways during the penetration process.
As shown in Fig. 15, the kinetic energy starts at the same values by Eqs (18) and (19). However, in the subsequent time steps, a large amount of the kinetic energy is transferred to internal energy (strain energy) for the high velocity impact while only a small amount kinetic energy is transferred to the internal energy under the low velocity impact condition.

\section{Conclusion}

A rate dependent MCT material damage module has been implemented and linked with LS-DYNA via a user-defined material routine (umat41). A rate dependent continuum damage mechanics approach was employed to compute the matrix damage and induced composite stiffness reduction. Different from the conventional MCT approach, a new damage tensor $\left(n_{i j}\right)$ and 


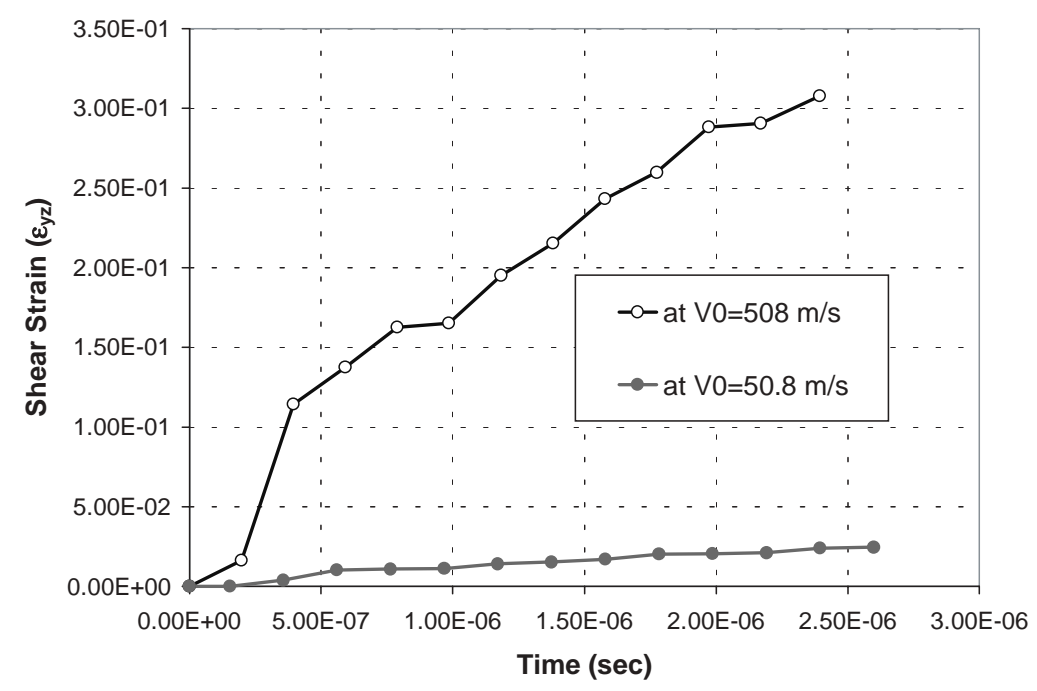

Fig. 11. A comparison of time history of shear strain $\left(\varepsilon_{y z}\right)$ of element 2184 at initial impact velocities of $50.8 \mathrm{~m} / \mathrm{s}$ and $508 \mathrm{~m} / \mathrm{s}$.

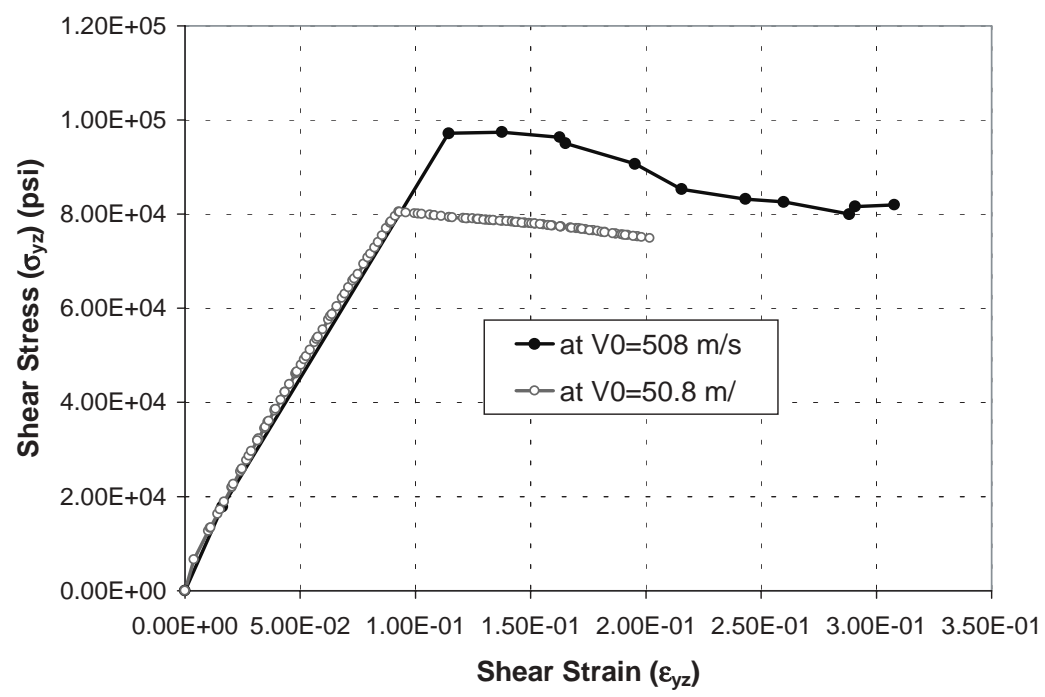

Fig. 12. A comparison of constitutive material response under yz-shear.

its associated invariants have been introduced during the progressive damage analysis. Both the matrix failure criteria and the material degradation have been formulated based on the invariants of the damage tensor.

The applicability of the developed LSDYNA-MCT solution module was first demonstrated through a one element model of a plain weave composite subjected to in-plane $(x y)$ shear loading. In this model, the nonlinear material response was demonstrated along with the associated constituent failure sequence and failure mechanisms.

The observed effects of strain-rate hardening from the one element model were further explored by mod- eling a composite panel subjected to both a low and high velocity impact. For these analyses, each projectile was given the same initial kinetic energy, with a resulting shear strain rate $\left(\dot{\varepsilon}_{y z}\right)$ at element 2184 (see Fig. 8) that was approximately 18 times higher under the high velocity impact $\left(V_{0}=508 \mathrm{~m} / \mathrm{s}\right)$ as compared with the low velocity impact $\left(V_{0}=50.8 \mathrm{~m} / \mathrm{s}\right)$. Also, the yield point in the constitutive shear stress/strain response rises from $0.55 \mathrm{GPa}$ at $V_{0}=50.8 \mathrm{~m} / \mathrm{s}$ to $0.69 \mathrm{GPa}$ at $V_{0}=508 \mathrm{~m} / \mathrm{s}$, a $25 \%$ increase due to the strain rate hardening. Because of the effect of strain hardening, the velocity of the projectile has been re- 


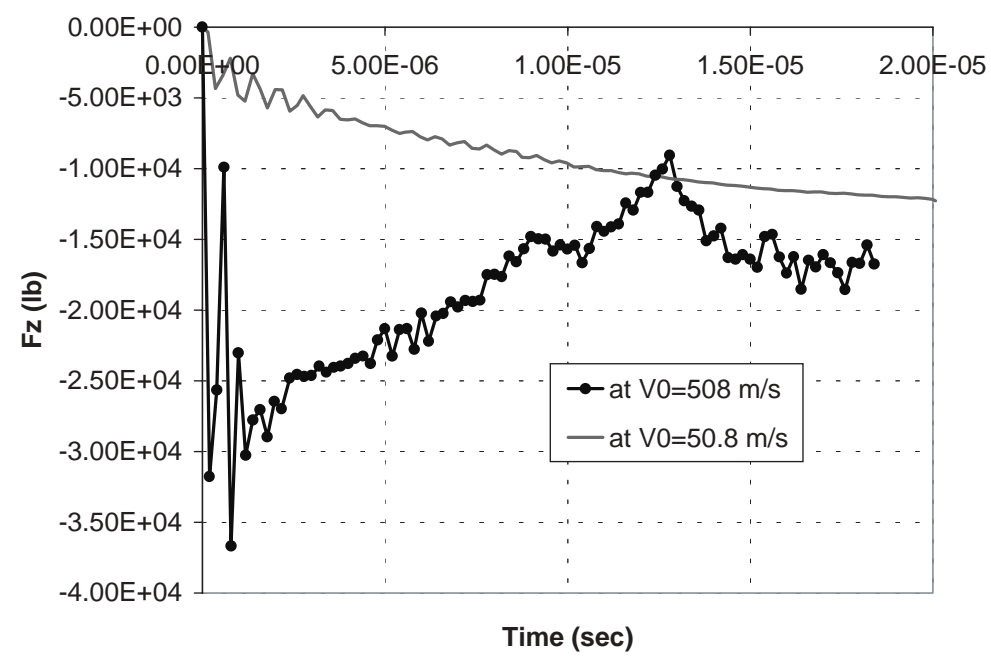

Fig. 13. A comparison of time history of z-component of the total contact force $\left(F_{z}\right)$ between the projectile and the composite plate.

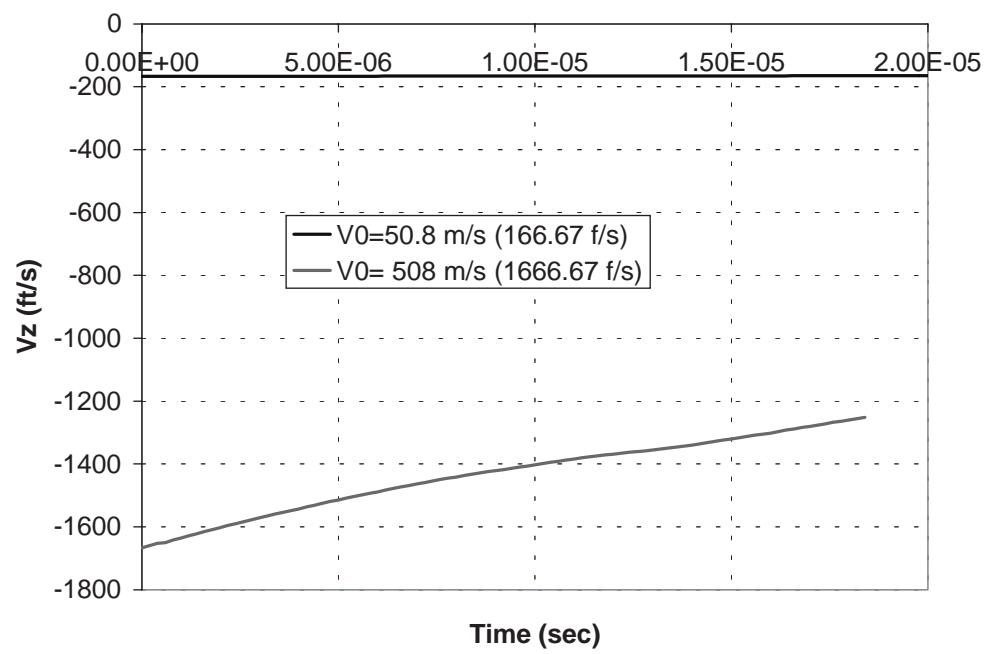

Fig. 14. A comparison of the time history of the z-component of projectile velocity.

duced under the high velocity impact with most of the energy stored as internal energy.

The results of these studies illustrate the presence of a large deviation of composite properties/response/failure mechanisms at various stain rates. Therefore, we can conclude that dynamic analyses run with static material properties will result in inaccurate failure predictions for extreme dynamic loading conditions.

In summary, the rate dependent LSDYNA-MCT has shown its capability in capturing the matrix cracking induced material nonlinearity and the strain rate hardening effect. To make the rate dependent MCT material damage model a quantitative dynamic damage assessment tool, two key issues must be addressed. First, de- lamination and disbonding failure modes must be added and validated within the MCT damage model. This will be accomplished through an additional constituent representing the bond strength at both the fiber-matrix interface and the lamina interface. Second, an experimental program must be established to determine the damage coefficients used in the damage evolution law for a given extreme dynamic loading. Prior to applying the tool to dynamic failure prediction of full-scale structural composite component, a limited number of calibration studies must be performed at the coupon level to determine the in-situ matrix damage parameters. Future studies will be focused on tool validation and tool enhancement. 


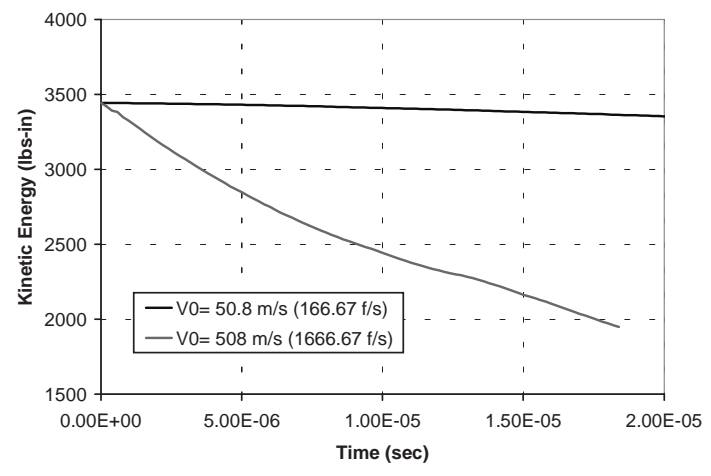

(Kinetic Energy)

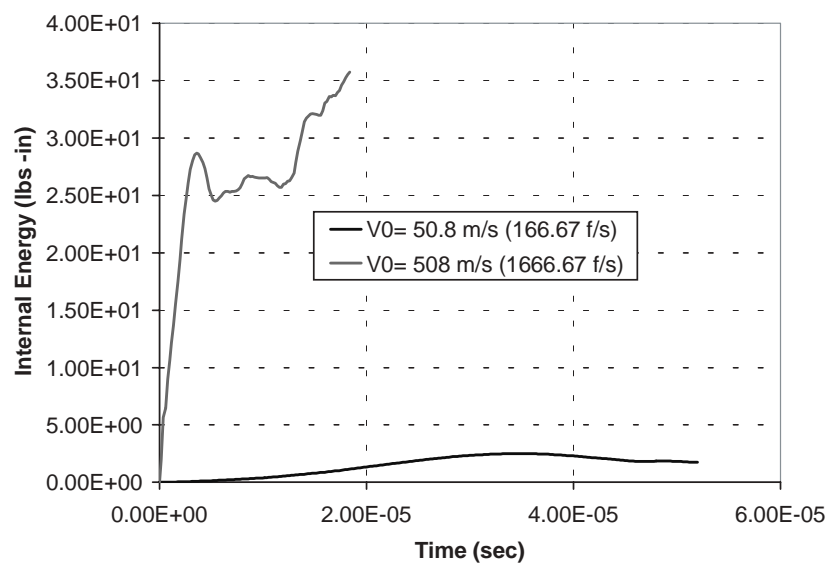

(Internal Energy)

Fig. 15. Comparison of time histories of kinetic/internal energies for low and high velocity impact.

\section{Acknowledgement}

Support from the Office of Naval Research (ONR) SBIR Program and ONR 334 under Contract N0001401-C00199 with Mr. Patrick Potter as Program Monitor is gratefully acknowledged.

\section{References}

[1] O. Akil, U. Yildirim, M. Guden and I.W. Hall, Effect of strain rate on the compression behavior of a woven fabric S2-glass fiber reinforced vinyl ester composite, Polymer Testing, In Press, 2003.

[2] A.C. Hansen and J. Baker-Jarvis, A Rate-Dependent Kinetic Theory of Fracture of Polymers, International Journal of Fracture 44 (1990), 221-231.

[3] C.T. Key, A Progressive Failure Analysis of a Plain Weave, Woven Roving, Composite Material, Master Thesis, University of Wyoming, 2000

[4] C.T. Key, R.W. Six and A.C. Hansen, A Three-Constituent Multicontinuum Theory for Woven Fabric Composite Materials, Composites Science and Technology 63(13) (2003), 18571864.

[5] J. Lua, J. O'Brien, C. Key and A. Hansen, Multicontinuum Failure Analysis of Woven Fabric Composite Structures Under Extreme Dynamic Loads, in Proceedings of the 73rd Shock \& Vibration Symposium, 2002.

[6] J.S. Mayes and A.C. Hansen, Multicontinuum Failure Analysis of Composite Structural Laminates, Mechanics of Composite Materials and Structures 8(4) (2001), 249-262.
[7] J.S. Mayes and A.C. Hansen, Composite Laminate Failure Analysis using Multicontinuum Theory, Part A of the Worldwide Failure Exercise sponsored by DERA, Great Britain, Composites Science and Technology 64(3-4) (2004), 379-394.

[8] J.S. Mayes and A.C. Hansen, A Comparison of Multicontinuum Theory Based Failure Simulation with Experimental Results, Part B of the Worldwide Failure Exercise sponsored by DERA, Great Britain, Composites Science and Technology 64(3-4) (2004), 517-527.

[9] F. Paris, A study of failure criteria of fibrous composite materials, NASA/CR-2001-210661, 2001.

[10] J. Rodriguez, I.S. Chocron, M.A. Martinez and V. SanchezGalvez, High strain rate properties of aramid and polyethylene woven fabric composites, Composites: Part B 27 (1996), 147154.

[11] S.C. Schumacher, A Multicontinuum Damage Model for Composite Materials Motivated by the Kinetic Theory of Fracture, Ph.D. Dissertation, University of Wyoming, 2002.

[12] S.V. Thiruppukuzhi and C.T. Sun, Models for the strain-ratedependent behavior of polymer composites, Composites Science and Technology 61 (2001), 1-12.

[13] S.W. Tsai and E.M. Wu, A General Theory of Strength for Anisotropic Materials, Journal of Composite Materials 5 (1971), 58.

[14] J.S. Welsh, J.S. Mayes and C.T. Key, Damage Initiation Mechanics, 43rd AIAA/ASME/ASCE/AHS Structures, Structural Dynamics, and Materials Conference, Denver, Colorado, 2002.

[15] S.N. Zhurkov, Kinetic Concept of the Strength of Solids, International Journal of Fracture 26 (1984), 295-307. 

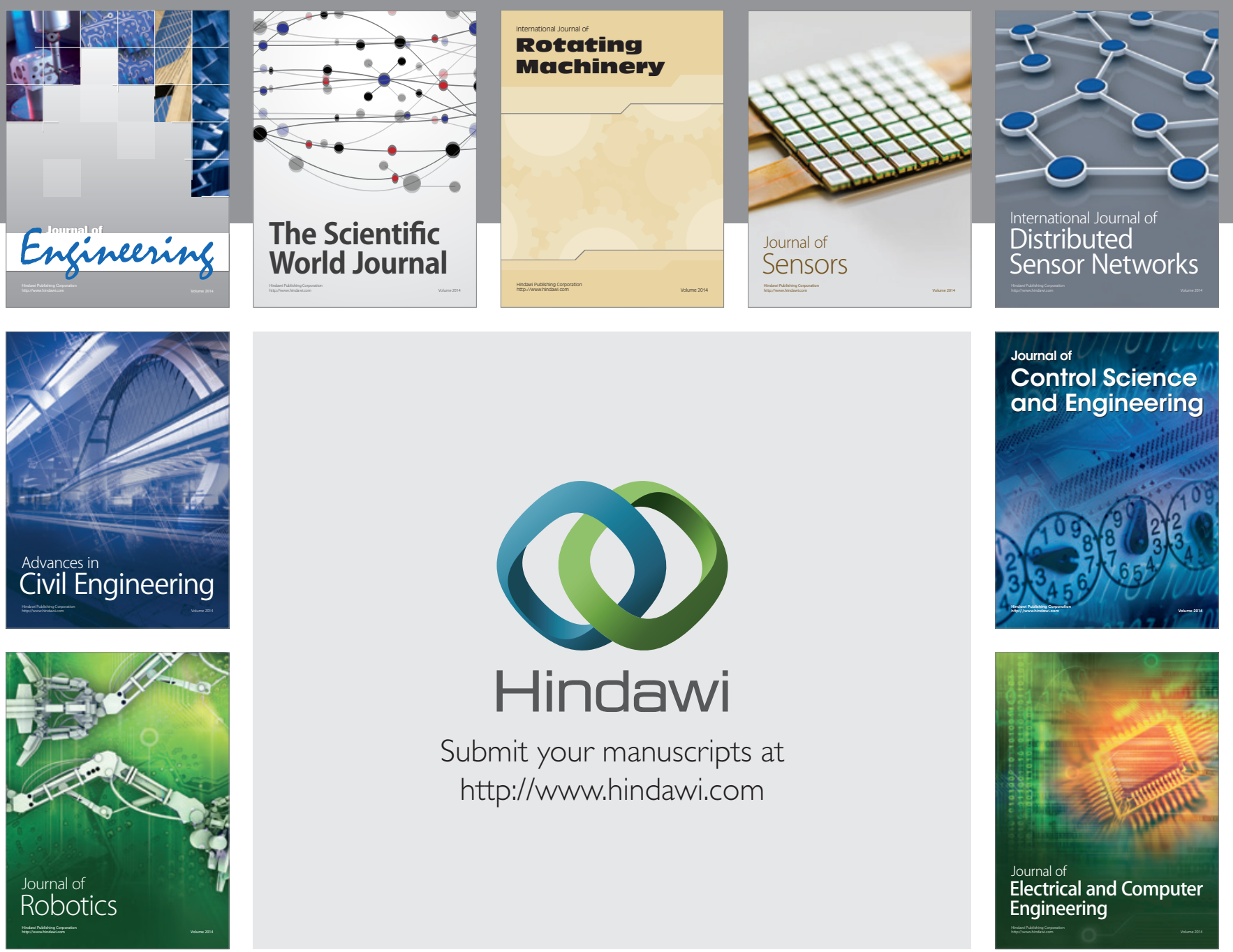

Submit your manuscripts at

http://www.hindawi.com
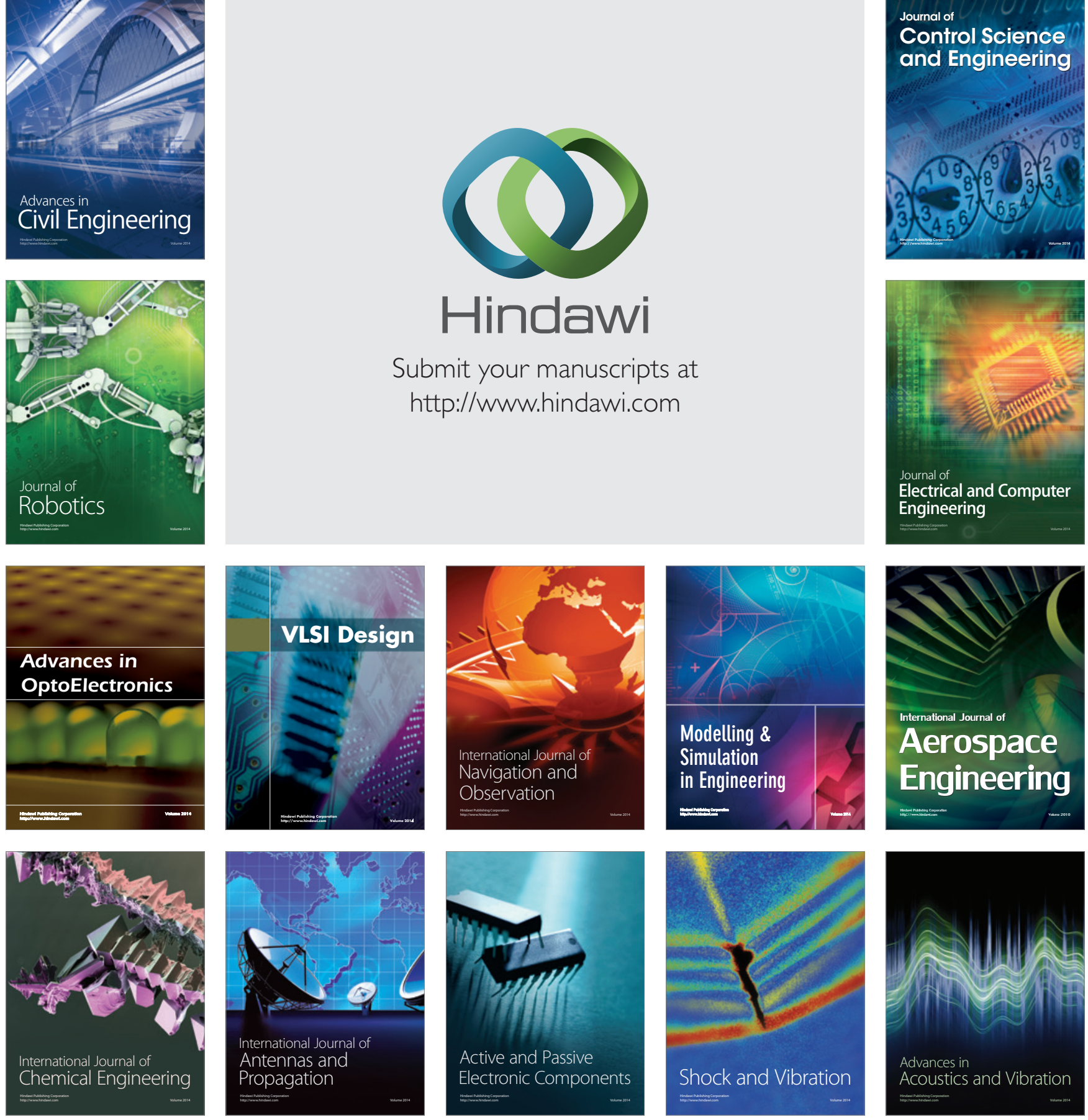